\title{
Forensic Analysis of Three Pets: Victims of Carbamate Intoxication
}

Tália Missen Tremori, Laila Massad Ribas, Mara Rita Rodrigues Massad, Luiz Maurício Montoya Flórez, Elan Cardozo Paes de Almeida and Noeme Sousa Rocha

Department of Veterinary Clinic, Campus Botucatu, UNESP - Univ Estadual Paulista, Brazil

*Corresponding author: Tália Missen Tremori, Department of Veterinary Clinic, Campus Botucatu, UNESP - Univ Estadual Paulista, Brazil, Tel: +55(14)99827-7318; Email: talia_missen@hotmail.com

Received date: January 15, 2017; Accepted date: March 03, 2017; Published date: March 06, 2017

Copyright: @ 2017 Tremori TM, et al. This is an open-access article distributed under the terms of the Creative Commons Attribution License, which permits unrestricted use, distribution, and reproduction in any medium, provided the original author and source are credited.

\begin{abstract}
Cases of intoxication are common in the history of the veterinary medicine, mainly in dogs and cats. Appropriate recognition of the clinical signs and pathological findings could characterize cases of intoxication, however laboratorial methods in forensic toxicology is fundamental to establish a definitive diagnosis of the toxic agent. In the present work was made analysis of three cases of pet animals criminally intoxicated by carbamate. Necropsy helps to uncover causes mortis, were verified cardiac respiratory insufficiency and hypovolemic shock in all cases. Histopathology exam of liver, kidney and brain described the main lesions like congestion, degeneration and haemorrhage. Organs show signs of autolysis and putrefaction. Therefore, diagnostic techniques helps veterinarian to make reports for litigation in animal criminal intoxication.
\end{abstract}

Keywords: Veterinary forensic medicine; Expertise; Toxicology; Forensic histopathology

\section{Introduction}

Over the years, forensic veterinary medicine has experienced a significant increase of performance and effectiveness also because a raise of social sensitivity to animal cruelty. Non-accidental intoxication is frequent, mainly exogenous. However, animal crimes often remain unreported [1,2].

Criminal intoxication falls among prohibited conducts indicted by the Environmental Crimes Law, No 9.605/98. Specifically, Article 32 typifies as a crime to perform acts of abuse, to injure or mutilate wildlife, domestic or domesticated, native or exotic, providing imprisonment from three months to one year, and additionally, a respective fine $[3,4]$.

According to previous studies, fatal intoxication occurs mainly due to pesticides, being $50.4 \%$ of cases caused by carbamates, $18.9 \%$ by anticoagulant rodenticides, $5.1 \%$ by organophosphate and $3.4 \%$ by non-anticoagulant rodenticides [5-7].

Non-violent deaths in animals should always be investigated to verify possible intoxication, because veterinarians routinely facing these cases [5,8-12].

On these terms, toxicology allows determining chemical action mechanisms in the body, clinical signs, post mortem characteristics (microscopic and macroscopic), necropsy findings, and toxic agent detection in order to get a reliable poisoning diagnosis. Evidence identification is extremely important to facilitate forensic investigation and necropsy report $[1,13,14]$.

Toxicants are substances able to damage health, or even result in death. Depending on gravity of signs and symptoms, poisoning syndrome is classified as mild, moderate or severe. Some factors, alone or in combination, contribute to its manifestations such as dose quantity, individual strength, exposure time, and the route of administration $[15,16]$.

If the animal dies, forensic necropsy and histopathologycal analysis, associated with a drug testing, are needed to reach an accurate diagnosis. Thus, the confirmation of suspected cases increases $[7,9,13,17,18]$.

Finally, necropsy report plays a key role by clarifying facts, and defining death cause. Likewise, forensic histopathology through a comprehensive tissue analysis is quite helpful for interpretation $[10,19,20]$.

\section{Material and Methods}

Three cases of pet intoxication were selected from records of the archives at Veterinary Pathology Service-FMVZ from July 2014 to January 2015. Although more cases have been found furthermore this study was requested only that were comply with all requirements: forensic necropsy reports, microscopy analysis, judicial requests, and toxicological examination.

The reports were documented by photographs (JPEG Image DSCH9) before undergoing necropsy. The autopsy technique was the modified Ghon, which consists of the opening of the skull and thoracoabdominal cavity to extract organs in anatomical and functionally related blocks, totaling four. Picked organs were removed from each block and examined in detail. Some of them were photographed (JPEG Image DSC-H9) for registry purposes [20].

Concurrently to necropsy, samples were collected for physical and chemical analysis, and histopathologycal conventional exam, regardless time of death. For the physical-chemical examination, duplicate samples of liver and kidney (30 gm) were harvested from each animal, then identified, packed and, sometimes, refrigerated.

One of the duplicate specimens was sent to the toxicology laboratory with the request form and death certificate, which included possible poisoning agents, in order to identify and quantify their 
chemical compounds. The other duplicate was kept in custody until obtaining toxicological official results, and later discarded, according biosecurity protocols.

For histological analysis, samples of kidney, liver and brain were placed into individual vials containing $10 \%$ buffered formalin, at minimum proportion of five times specimen size. It remained so until processing, according to conventional methods. Thickness of cuts ranged from 4.0 to 5.0. Staining was made by using Hematoxylin and Eosin (H\&E)

For morphological expression of lesions in brain, kidney and liver, from both macroscopic and microscopic perspectives, the criteria contained in referential textbooks prevailed. In this case, characterizations were focused on lesions caused by the action of toxic compounds, especially on those causing degeneration and other types of non-reversible damage to cells or tissues comprising such organs $[19,21,22]$.

\section{Results}

The first animal was a four-year male dog, non-defined breed (NDB), positive for carbamate by a qualitative drug testing. Macroscopic study showed a whitish and frothy fluid at the final third of the trachea, extending to larger bronchi. Lung displayed extensive reddish and crackling areas. Stomach had a moderate foamy yellowish liquid along with a substance of granular aspect and blackened shade. A discrete hepatomegaly with an intense red color was found at liver. Pancreas had a softened consistency. Sulfhemoglobin stains were on the outer surface of spleen, which characterize a decomposition process. Moderate blood vessels with a dark red color were also detected in brain and skeletal muscles of the skull.

On microscopic examination, liver revealed a marked microvacuolation and degenerate hepatocytes near lobular vein center with the presence of "ghost" cells. A significant trabecular congestion was verified by the presence of large quantities of erythrocytes in blood vessels. Kidneys had congestion and microcalcifications.

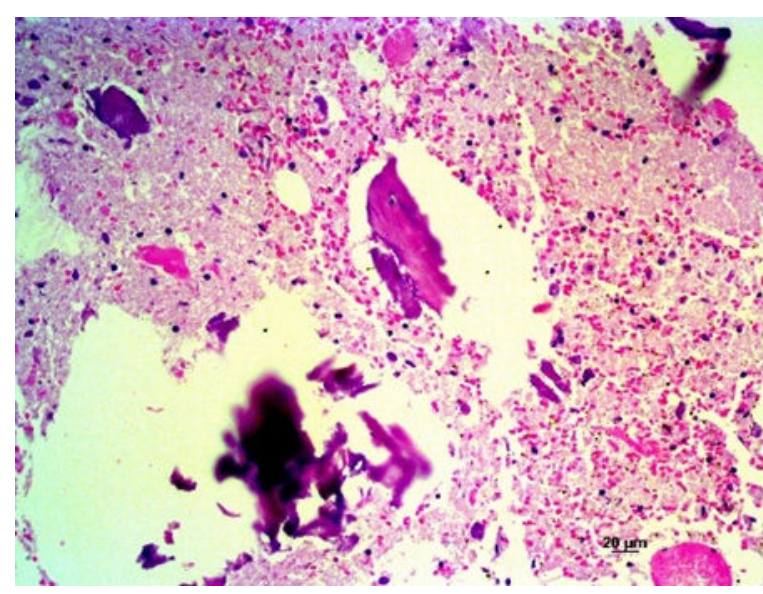

Figure 1: Dog brain: Bone tissue in the cerebral cortex hemorrhage (H\&E 20X).

The cortical and medullary vessels were bleeding with an intense and diffuse blockage. Tubular cells showed a severe vacuolation and a moderate quantity of hyaline material in the glomerular space. In some renal regions, degenerate cells detached from the basement membrane and massive pyknotic nuclei were present, all related to autolysis of parenchyma.

Brain evaluation unveiled a moderate disseminated intravascular coagulation (DIC), absence of inflammation, rare satellite cells nearby to neurons. In the gray matter, a region with bone tissue, head trauma indications and bruises appeared. This coincides with lesions verified by microscopy of erythema on temporal muscles covering skullcap. Besides, moderate bleeding was located in meninges and cerebral cortex (Figure 1).

A histopathologycal examination of lungs disclosed edema, pulmonary congestion and a severe CID, mainly due the presence of adhered red blood cells at the vessel wall, beyond a critical bleeding to the alveolar sacks by eritrocytes extravasation. The second case is related to an 8-month female feline, also NDB, positive for carbamate by a qualitative toxicology exam. At necropsy, an off-white and foamy liquid in the final third of the trachea was observed, extending to bronchial area with a deposition of blood with hypostasis at the left side of lung. Likewise, there was a moderate amount of unidentified food in the stomach, mixed with blackened granules. Encephalon presented evident lesions in blood vessels (Figure 2).

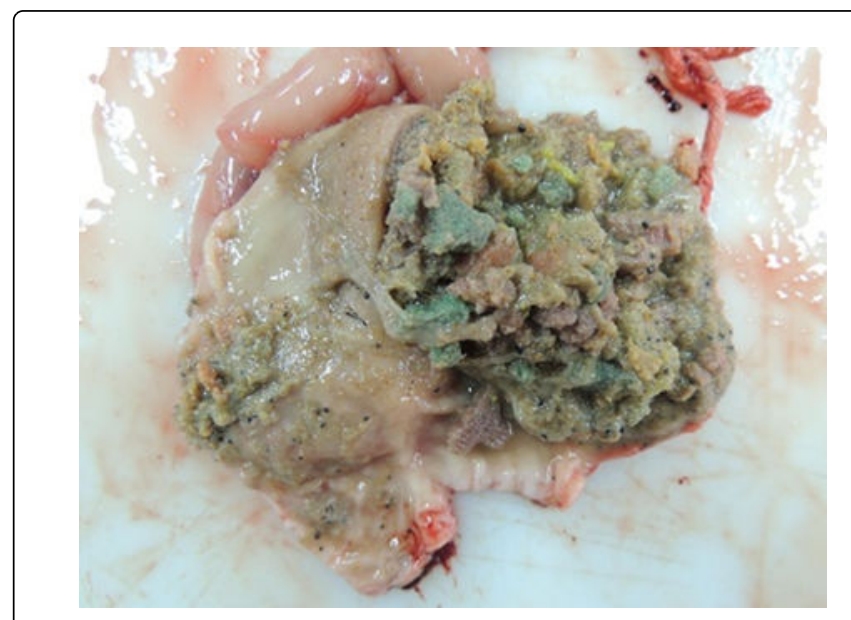

Figure 2: Cat stomach: Blackened particles intermingled with food content (carbamate)

As for microscopic examination of liver, vacuoles close to portal space featured a pronounced fatty degeneration, and macroglandular steatosis. Brownish spots indicated biliary stasis (cholestasis), and a mild vascular congestion.

Kidneys demonstrated vascular congestion within medullary and profuse hemorrhage areas. Vacuoles at renal tubule cells of the cortex pointed to a minor fatty degeneration, and cell separation from basal membrane (Figure 3). In the brain, there was an incipient congestion and a moderately diffuse lung edema, followed by intra-alveolar bleeding.

The third considered sample was a 12 -year female canine, SRD, also tested positive for carbamate. After forensic exam, a whitish-reddish frothy liquid was in the final third of the trachea, extending to the bronchi. Lungs displayed yellow irregular areas to multifocal coalescing. 


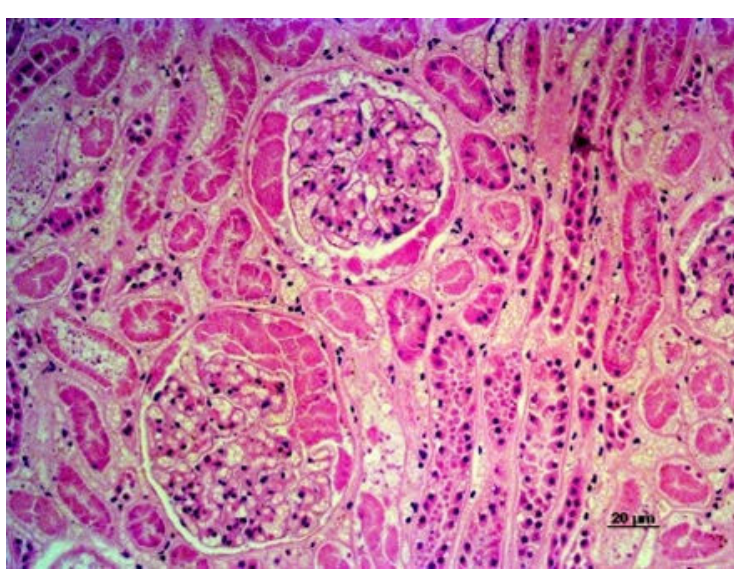

Figure 3: Cat rim cortical region: Detachment from the basement membrane (H\&E 20X).

Spleen had multiple nodules with whitish appearance, firm consistency, and irregular capsular surface, of approximately $1.5 \mathrm{~cm}$ diameter in average. Liver exhibited bulging lips, distended gallbladder, and filled of bile with lumpy appearance. Stomach lumen was filled by blackish liquid, greenish paste content in the bowel, presence of edema in the gastric and intestinal wall. Renal examination revealed capsular adherence in both kidneys, reddish subcapsular region, and expanded pelvis. Urinary bladder contained a whitish thick fluid.

Under microscope, liver tissue showed diffuse multifocal areas, large quantities of degenerate hepatocytes, mainly near the centrilobular region. Vascular congestion and diffuse areas with moderate bleeding also were watched. Kidneys presented a moderate infiltrate multifocal lymphoplasmacytic at the cortical region, extending to spinal area, vascular congestion with a slight hemorrhage. In fact, both organs suffered from acute tubular necrosis (ATN).

Brain was slightly congested with some red blood cells adhered to the capillary internal layer, and a light bleeding. A sharp pulmonary edema was characterized by eosinophilic amorphous material, prominent hemorrhage at interstitial region and vascular congestion.

\section{Discussion}

Histological knowledge is essential for a proper understanding of the structure and functioning of cells, tissues and organs. After removing fragments for histopathological evaluation, samples must be preserved by fixation in order to prevent enzymatic tissue digestion, or autolysis, by the own cells. Commonly, forensic necropsies and specimens sent for examination are under decomposition. However, once received by the forensic staff, all material must be processed, and supported, in any case, by a technical report. If the sample quality affects the outcome, this information should be amended [23].

Liver acts as an interface between the digestive tract and blood. In this organ, nutrients are absorbed through the portal circulation, via the portal vein and hepatic artery, and later processed and stored.

In addition, the liver is the main organ performing the biotransformation. This chemical modification comprises a set of enzymatic reactions that alter activity and physical properties of various endogenous and exogenous compounds. Hepatic biotransformation develops two phases involving primarily the cytochrome P450 enzymes, mainly located in the microsomes of the endoplasmic reticulum of hepatocytes, especially those closer to the centrolobular vein (Rappaport zone III). The first phase accomplishes substance oxidation by cytochrome $\mathrm{P} 450$. Then, the resulting product is combined for excretion at the second phase. As a result, toxic or non-toxic metabolite formation occurs [24].

If, during the poisoning, the dose ingested by the animal is high, degeneration is possible to be seen in areas other than the region near the centrolobular vein. In acute poisoning, as the studied cases, zone I of the liver is the most affected by an intense deterioration of hepatic stem cells. This decomposition process is characterized by voids in the cytoplasm known as vacuoles.

Acute intoxication is not sufficient to trigger edematous responses. Consequently, inflammatory cells resulting from other processes will further exacerbate liver degeneration.

After death, liver autolysis begins immediately, due to the large amount of enzymes. Thus, the cadaveric phenomena change, rapidly and easily, organ structure, which can compromise histological evaluation.

The coagulative hepatocellular necrosis also occurs commonly in toxic injury, which may be focal or multifocal. In this case, the tissue architecture is normal. Hepatocytes with karyolytic, karyorrhexistic, and piknotic cores, and acidophilic cytoplasm are present [22].

Cholestasis (biliary steatosis) occurs by hepatocyte deterioration. In this way, a common finding is established in the hepatic histology of animals dying by poisoning, since chemical compounds highly promote functional cell degradation in this organ. Likewise, the deposition of hemosiderin is usual because an increased destruction of red blood cells in the tissue. In the case of a fatal acute poisoning, observing hepatic fibrosis is unlikely. Nevertheless, if the animal survives, this lesion can be one of those irreversible since Ito cells, located between hepatocytes, gather vitamin A. When damaged, these cells lose fat granules and synthesize collagen, which is important to the fibrogenesis process.

Among post-mortem changes, liver coloration is very sensitive. It can be modified by the following facts: cadaveric lividity; print marks caused by pressure of ribs, leaving some areas with paler coloring; hemoglobin impregnation, becoming dark red; false melanotic in contact with the bowel, by eliminating hydrogen sulfide combined with the iron released by erythrocytes lysates causes greenish color; and gall soaking leaving yellowish spots [22].

Kidneys perform glomerular filtration, reabsorption, and tubular secretion. Chemicals typically induce renal injury for different reasons: glomerular epithelial cells can undergo a direct lesion; changes occurred in renal blood flow; and immunocomplex formation, especially by acute exposure, such as the case of toxic agents.

As noted, the tubular epithelium cells, primarily in the proximal tubules, are more susceptible to ischemia and nephrotoxins because its high metabolic activity and the amount of glomerular filtrate reabsorbed during urine formation process [25].

In toxic damages, hyperemia is manifested with blood stasis. Macroscopically, cuts reveal increased blood flowing on the surface, actually redder. Microscopically, all blood vessels, especially capillaries, are congested, matching the literature [26]. 
Acute tubular necrosis (ATN) is the leading cause of kidney failure. Generally, ATN results from degenerative nephrotoxic lesions to kidney epithelial tubules. The microscopic appearance of kidney varies depending on damage grade, exposure time to the toxic agent, and the interval between lesion and death. Histological examination disclosed an extensive necrosis of proximal tubules with, or without, basal membrane preservation. Lesions with greater intensity were in the cortex, and into a lesser extent, in the renal marrow [27,28].

An important aspect is to realize the existence of deadly diseases of neurological origin with, or without, macroscopic or microscopic changes on nervous tissue, such as intoxication by strychnine, carbamate, and organophosphate. As a result, pathologist must proceed through toxicology techniques [29].

Finally, correlation among findings of illegal poisoning cases here described matches what literature points out. Therefore, strengthening forensic veterinary pathology becomes a very important matter for the suitable completion of necropsy report [30].

\section{Conclusion}

Based on macroscopic and microscopic interpretation of anatomopathological findings related to illegal poisoning of dogs and cats, it can be concluded that the use of histopathological and toxicology techniques were complementary. The analysis of cell and tissue alterations in some organs, along with toxicant agent tests, facilitated the understanding of criminal intoxication in selected samples. Thus, applying proper techniques of veterinary legal medicine can contribute to produce material evidence for the benefit of judicial processes involving animals.

\section{Acknowledgement}

CAPES (Coordination and Improvement of Higher Education Personnel Development) - Brazil.

\section{References}

1. Gwaltney-Brant SM (2007) Epidemiology of animal poisoning Veterinary Toxicology, Elsevier, pp: 67-73.

2. Marlet EF, Maiorka PC (2010) Retrospective analyzes of cruelty toward dogs and cats in the city of São Paulo. Braz J Vet Res Anim Sci 47: 385-394.

3. Brazil Law no. 9605 (1998) Law of Environmental Crimes. Brasília: Official Federal Gazette, Brazil.

4. Brazil Law No. 5517 (1968) Regulates the exercise of Veterinary Medicine in Brazil: Official Gazette of the Union, Brazil.

5. Wang Y, Kruzik P, Helsberg A, Helsberg I, Raush WD (2007) Pesticide poisoning in domestic animals and livestock in Austria: A 6 years retrospective study. Forensic Sci Int 169: 157-160.

6. Xavier FG, Righi DA, Spinosa HS (2007) Fatal poisoning in dogs and cats: A 6 year report in a veterinary pathology service. Braz J Vet Res Anim Sci 44: 304-309.

7. Medeiros RJ, Monteiro FO, Silva GC, Nascimento AJr (2009) Poisoning dogs and cats attended in the Veterinarian College in Federal Fluminense University during the period of 2002 to 2008 . Cienc Rural 39: 2105-2110.
8. Bulcão RP, Tonello R, Piva RJ, Schmitt GC, Emanuelli T, et al. (2010) Intoxication in dogs and cats: toxicological diagnosis using thin layer chromatography and high pressure liquid chromatography with ultraviolet detection in stomach samples. Cienc Rural 40: 1109-1113.

9. Byard RW, Boardman W (2011) The potential role of forensic pathologists in veterinary forensic medicine. Forensic Sci Med Pathol 7: 231-232.

10. Cooper JE, Cooper ME (2008) Forensic veterinary medicine: a rapidly evolving discipline. Forensic Sci Med Pathol 4: 75-82.

11. Berny P, Caloni F, Croubele S, Sachana M, Vandenbroucke V, et al. (2010) Animal poisoning in Europe. Part 2: Companion animals. The Vet J 183: 255-259.

12. Mcdonough SP, Gerdin J, Wuenschmann A, Mcewen BJ, Brooks JW (2015) Illuminating Dark Cases Veterinary Forensic Pathology Emerges. Vet Pathol 52: 5-6.

13. Cooper JE, Cooper ME, Future trends in forensic veterinary medicine. Semin Avian Exot Pet Med. 7: 210-217.

14. Marlet EF, Yoshida AS, Gorniak SL, Maiorka PC (1998) Elaboration of expertise report in veterinary medicine. CFMV Journal 55: 12-19.

15. Munro R (1998) Forensic necropsy. Semin Avian Exot Pet 7: 201-209.

16. Below E, Lignitz E (2003) Cases of fatal poisoning in post-mortem examinations at the Institute of Forensic Medicine in GreifswaldAnalysis of five decades of post-mortems. Forensic Sci Int 133: 125-131.

17. Klaassen CD, Watkins JB (2012) Fundaments in toxicology. McGraw-Hill Education, New York, USA.

18. Klaassen CD, Casarett LJ, Doull J, Klaasen CD, Casarett et al. (2013) Casarett and Doull's toxicology : the basic science of poisons. (8th edtn), McGraw-Hill Education, New York, USA.

19. Cummings PM, Trelka DP, Springer KM (2011) Poisoning. In: Atlas of forensic histopathology. Cambridge University Press, New York, USA.

20. Prestes Junior LCL, Ancillotti R (2009) Manual of medical-legal necropsy techniques. Blonde publisher, Brazil.

21. Jubb KVVF, Kennedy PC, Palmer NC (2007) Pathology of Domestic Animals, Saunders Elsevier, Edinburgh, USA.

22. Volmer PA, Meerdink GL (2002) Diagnostic Toxicology for the Small Animal practitioner. Vet Clin North Am 32: 357-365.

23. Junqueira LCU, Junqueira LMMS (1983) Basic techniques of cytology and histology. Santos publisher, Portugal.

24. Carlton WW, Mcgavin MD (1998) Special Veterinary Pathology of Thompson. (2nd Edn), Artmed Publishers, Porto Alegre, Brazil.

25. Serakide R, Sistema Urinário (2010) In: Santos RL, Alessi AC Veterinary Pathology. Roca Publishers, Sao Paulo, Brazil pp: 291-336.

26. Kumar V, Abbas AK, Fausto N, Aster JC (2009) Robbins and Cotran Pathologic Basis of Disease (9th Edn), Saunders Company, Philadelphia, USA.

27. Rocha NS, Bacchi CE, Carvalho M, Schmitt D, Schmitt F et al.(1994) Immunohistochemical characterization of probable intravascular haematopoesis in the vasa recta of the renal marrow in acute tubular necrosis. Pathol Res Prac 190: 1066-1070.

28. Mcgavin MD, Zachary JF (2013) Pathologic basis of Veterinary Pathology. (5th edn), Elsevier publishers, São Paulo, Brazil.

29. Graça DL, Alessi AC, Ecco R, Viott AM, Patologia Do Sistema Nervoso (2010) In: Santos RL, Alessi AC Veterinary Pathology. Roca Publishers, Sao Paulo, Brazil pp: 525-610.

30. Tremori TM, Rocha NS (2013) The examination of the corpus delicti in veterinary expertise. Journal of Continuing Education in Animal Science of CRMV-SP. Legal Veterinary Medicine 11: 30-35. 